\title{
Pendeteksian Gerakan Menggunakan Transduser Ultrasound dengan Metoda Pembandingan Pola Gema
}

\author{
Motion Detection using Ultrasonic Sensor with Echo Pattern Comparison \\ Method
}

\author{
Dicky Rianto Prajitno, Ade Ramdan \\ Pusat Penelitian Informatika-LIPI
}

Jl. Sangkuriang 21 Bandung

Email: dicky@informatika.lipi.go.id; ade@informatika.lipi.go.id

\begin{abstract}
In this paper we propose a method of motion detection. The motion detection is performed by comparing two echoes pattern with a certain time interval, and the interval between certain pattern of objects's echoes. The distinction of the echoes pattern are indicating that several movement occur in the surrounding sensor area. With this comparison method, the sensor becomes sensitive to any objects movement in it's detection area. The result show that the sensor specifically is more sensitive in detection small movements compared to PIR sensor. In practice, this method was able to detect several human body movements such as walking, sitting, talking, and even be able to detect the movement of the body caused by human respiratory.
\end{abstract}

Keywords: ultrasound, motion sensor, pulse echo ranging, echo pattern

\begin{abstract}
Abstrak
Pada tulisan ini kami mengusulkan metoda pendeteksi gerakan. Pendeteksian dilakukan dengan cara membandingkan dua buah pola gema dalam interval waktu tertentu dan jeda antara pola gema. Perbedaan pola gema menunjukkan terjadinya gerakan dari benda-benda di area deteksi sensor. Dengan metoda pembandingan ini, sensor menjadi sensitif terhadap gerakan atau perubahan posisi setiap objek yang berada disekitarnya. Hasil yang diperoleh memperlihatkan bahwa sensor ini secara khusus lebih sensitif dibandingkan sensor PIR dalam mendeteksi gerakangerakan kecil. Pada prakteknya metoda ini telah mampu mendeteksi beberapa gerakan tubuh manusia seperti: dari mulai berjalan; duduk; berbicara; hingga gerak respirasi tubuh.
\end{abstract}

Kata kunci: ultrasound, deteksi gerakan, pulse echo ranging, pola gema

\section{Pendahuluan}

Saat ini banyak aplikasi yang membutuhkan sebuah pendeteksi gerakan[1], seperti pada aplikasi pengamanan, pengawasan, sistem otomatis[2], game[3], dan lain-lain. Pada sistem otomatis seperti misalnya pintu otomatis, atau juga saklar lampu otomatis, dibutuhkan alat yang dapat mendeteksi keberadaan manusia. Salah satu cara untuk mendeteksi keberadaan manusia adalah dengan mendeteksi gerakan.

Satu ciri manusia sebagai mahluk hidup adalah manusia akan selalu bergerak, entah itu gerakangerakan besar/kasar seperti berjalan, dan berbicara, ataupun hanya sebatas gerakan-greakan kecil/halus seperti bernafas.

Received: 30 Juni 2014; Revised: 12 Desember 2014; Accepted: 21 Januari 2015 ; Published online: 30 April 2015 (C)2014 INKOM 2014/14-NO246
Terdapat beberapa jenis sensor pendeteksi gerakan yang banyak diaplikasikan, misalnya: Pyroelectric Infrared (PIR)[4], kamera video, Ultrasound, dan Microwave[5]. Masing-masing sensor memiliki karakteristik sensitifitas, resolusi, dan instalasi yang berbeda.

Pendeteksi gerakan kebanyakan menggunakan sensor PIR karena kepraktisannya, sayangnya resolusi deteksi yang rendah dan sifat line of sight menjadikan kendala pada beberapa kasus aplikasi[6]. Pada tulisan ini, diusulkan sebuah metoda untuk mendeteksi gerakan berbasis gelombang ultrasound. Metoda ini memiliki resolusi yang lebih baik, sehingga dapat mendeteksi gerakan-gerakan kecil yang tidak terdeteksi oleh PIR[7].

Organisasi penulisan adalah sebagai berikut: bagian pertama adalah pendahuluan, pada bagian kedua dijelaskan mengenai metoda deteksi gerakan dengan pembandingan pola gema, pada bagian 
ketiga dijelaskan mengenai setup percobaan, pada bagian keempat dijelaskan mengenai hasil dan pembahasannya, dan bagian kelima adalah kesimpulan.

\section{Metoda Deteksi Gerakan dengan Pembandingan Pola Gema}

Metoda pengukuran jarak sebagai salah satu teknik pendeteksian gerakan dapat digambarkan seperti diperlihatkan pada Gambar 1. Metoda pulse echo ranging memanfaatkan laju cepat rambat gelombang akustik pada medium, dimana laju cepat rambat gelombang akustik di medium udara adalah $344 \mathrm{~m} / \mathrm{s}$ [8].

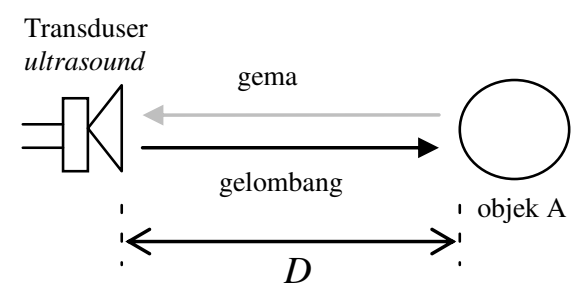

Gambar 1. Transduser ultrasound dengan sebuah objek. diam

Metoda ini mengukur selang waktu yang dibutuhkan oleh gelombang dari mulai saat dipancarkan hingga gemanya diterima kembali. Persamaan untuk menentukan jarak objek terhadap sumber adalah sebagai berikut:

$$
D=\frac{t . v}{2}
$$

dimana:

$D$ adalah jarak dalam satuan meter,

$t$ waktu tempuh gelombang dalam satuan detik,

$v$ adalah cepat rambat gelombang akustik di medium, $($ udara $=343 \mathrm{~m} / \mathrm{s})$.

Gambar 2 memperlihatkan pola gema dan selang waktu $\left(t_{1}-t_{0}\right)$ yang didengar oleh penerima dari objek A.

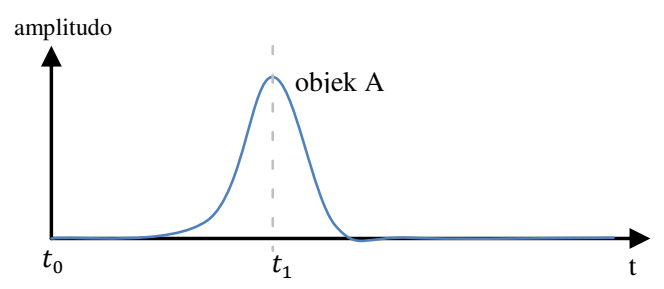

Gambar 2. Pola gema dari objek A.

Pada prakteknya jika terdapat lebih dari satu buah gema yang terdeteksi, maka yang diukur adalah gema pertama terdeteksi, sedangkan gema-gema berikutnya akan diabaikan. Pulse echo ranging biasa digunakan pada pengukuran jarak, seperti sensor parkir pada mobil.

Hampir sama dengan metoda pulse echo ranging, pada pembandingan pola gema, pemancar akan mengirimkan gelombang pulsa. Objek-objek disekitar sensor akan memantulkan gema, kemudian gema ini direkam dalam interval waktu tertentu. Untuk mengetahui ada atau tidaknya pergerakan benda-benda di area deteksi, maka dua buah pola gema yang telah direkam akan dibandingkan, untuk kemudian dilihat apakah terdapat perbedaan bentuk kedua pola tersebut atau tidak. Jika ternyata terdapat perbedaan diantara keduanya, maka dapat disimpulkan bahwa telah terjadi pergerakan objek-objek di sekitar sensor [11].

Ilustrasi pada Gambar 3.a sampai dengan Gambar 3.g dibawah ini dapat menggambarkan metoda yang dimaksud. Sebuah transduser ultrasound memancarkan gelombang ultrasound ke arah dua buah objek: A dan B. Objek A dalam posisi diam, sedangkan objek B bergerak mendekati transduser seperti pada Gambar 3.a. Kemudian gema yang dihasilkan kedua objek tersebut ditangkap kembali oleh transduser dan kemudian dilakukan sampel data pola gema sebanyak dua kali dalam jeda waktu tertentu, seperti yang diperlihatkan pada Gambar 3.d dan Gambar 3.e.

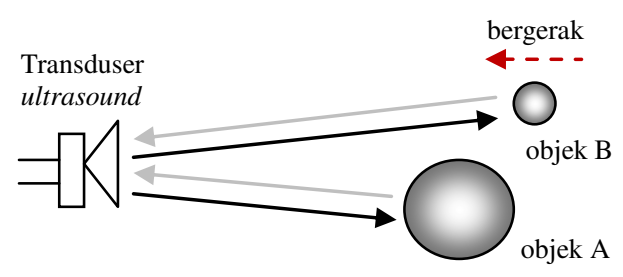

Gambar 3.a. Transduser ultrasound dan dua buah objek yang berbeda

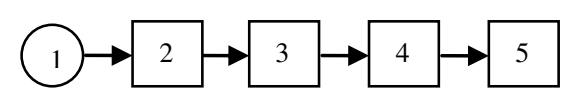

Gambar 3.b. Diagram blok sistem.

Diagram blok sistem seperti yang diperlihatkan pada Gambar 3.b., dengan urutan sebagai berikut: $1=$ transduser ultrasound, $2=\mathrm{ADC}, 3=$ memori, 4 $=$ komparator.

Transduser ultrasound akan memancarkan gelombang ultrasonik dan kemudian menangkap gema dari benda-benda disekelilingnya, gema tersebut kemudian didijitalisasi selama selang waktu tertentu menggunakan ADC dan membentuk sebuah pola gema. Pola gema ini kemudian disimpan pada dua buah array di dalam 
memori. Kemudian komparator akan membandingkan kedua buah pola tersebut.

Transduser yang digunakan berupa envelope detector, contoh keluaran transduser envelope detector seperti diperlihatkan pada Gambar 3.c.

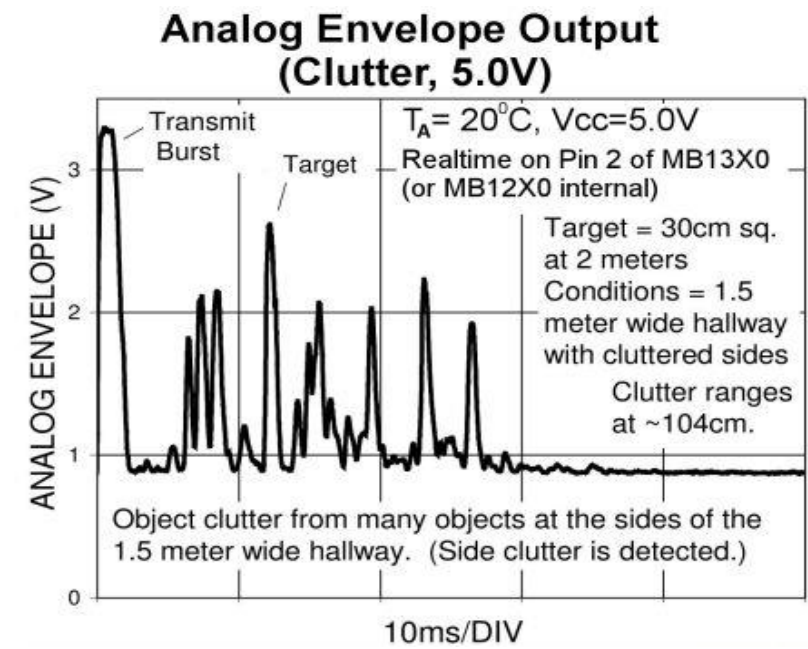

Gambar 3.c. Keluaran analog envelope dari transduser ultrasound MaxBotix1360[11].

Gambar 3.d memperlihatkan grafik sinyal gema dari objek A yang diam, dan sinyal gema dari objek B sebelum berpindah posisi (sebelum bergerak).

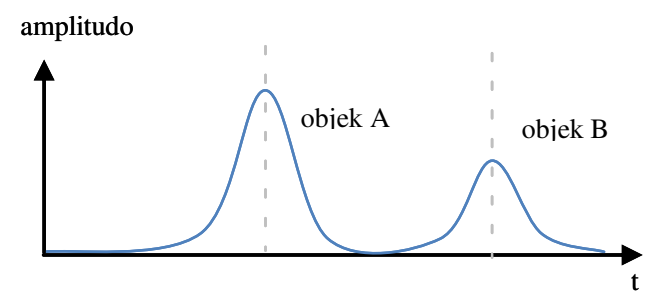

Gambar 3.d. Pola gema pertama objek A dan objek B.

Gambar 3.e memperlihatkan grafik sinyal gema dari objek A yang diam, dan sinyal gema dari objek B setelah berpindah posisi (setelah bergerak).

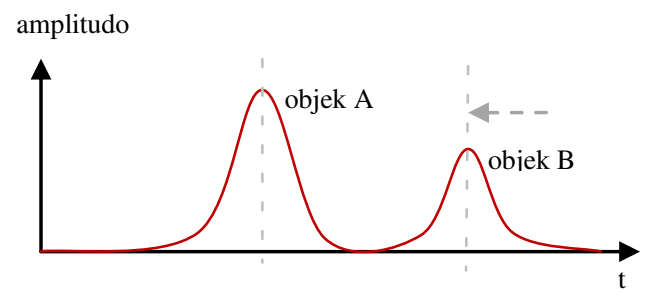

Gambar 3.e. Pola gema kedua objek A dan objek B, Objek B bergerak mendekati sensor.
Gambar 3.f memperlihatkan perbandingan grafik sinyal gema dari objek A yang diam, dan sinyal gema dari objek B setelah berpindah posisi, akan terdapat perbedaan kurva dari gema objek B yang akan merubah fasa dan amplitudonya[9].

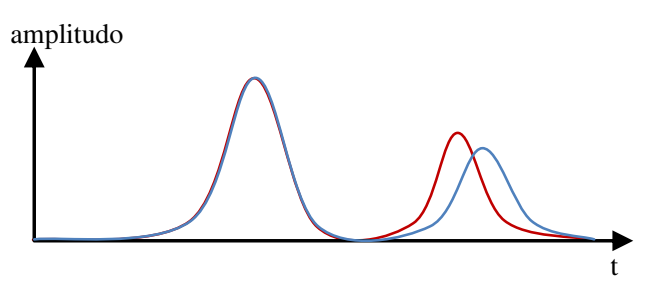

Gambar 3.f. Perbandingan pola gema benda ke 1 terhadap benda ke 2 .

Gambar 3.g. memperlihatkan selisih dari penjumlahan kedua pola gema tersebut.

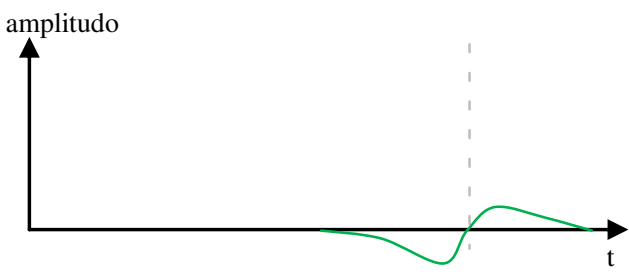

Gambar 3.g. Selisih pola gema pertama terhadap pola gema kedua.

Integral dari selisih kedua sinyal ini secara relatif memperlihatkan seberapa besar pergerakan yang terjadi.

Secara sederhana jika kuantitas selisih amplitudo kedua pola gema tersebut tidak sama dengan nol maka berarti sensor mendeteksi adanya gerakan dari benda-benda di area cakupannya[9,10].

Dengan menggunakan ADC pola gema tersebut disampling dan dikuantisasi, kemudian disimpan didalam array data $\boldsymbol{q}$. Terdapat dua buah array data gema, yang terdiri dari array data gema sebelumnya $\boldsymbol{q}^{\prime}$, dan array data gema sekarang $\boldsymbol{q}$. Data tersebut dibandingkan untuk setiap nilai kuantisasi $\boldsymbol{m}_{\boldsymbol{n}}$, kemudian diakumulasi $\boldsymbol{M}$.

Persamaan selisih absolut untuk setiap nilai kuantisasi adalah:

$$
m_{n}=a b s\left[q_{n}^{\prime}-q_{n}\right]
$$

Dan nilai total dari selisih kuantisasi adalah:

$$
M=\sum_{0}^{n} m_{n}
$$

Pada prakteknya digunakan threshold untuk mengeliminasi noise dari gema-gema yang tidak diinginkan, sehingga persamaannya menjadi seperti dibawah ini. 
$\therefore M=\sum_{0}^{n} f\left(m_{n}\right)=\left\{\begin{array}{cc}0, & m_{n} \leq \text { threshold } \\ m_{n}, & m_{n}>\text { threshold }\end{array}\right.$

Untuk mengatur sensitifitas sistem terhadap gerakan maka dapat kita atur pada besaran berapa sistem akan bereaksi. Pada prakteknya besaran ini bisa kita dapatkan dari percobaan di lab.

\section{Setup Percobaan}

Pembandingan pola gema dilakukan dengan membandingkan dua buah pola gema yang sebelumnya telah direkam ke dalam array. Masing-masing pola gema diambil sampel sebanyak 200 buah, dengan lama pengambilan data sebesar $45 \mathrm{~ms}$ agar didapat jarak tempuh gelombang terjauh yang dapat direkam sebesar sekitar 15 meter. Selang waktu pengambilan pola gema pertama dan kedua adalah sepertiga detik, dengan pertimbangan optimalisasi pada pengukuran gerak tubuh manusia, dari gerakan eksternal seperti gerak kaki berjalan, gerak tangan, dan juga gerakan internal yaitu gerak tubuh saat bernafas (proses respirasi eksternal).

Pengambilan sampel menggunakan ADC dengan resolusi kuantisasi sebesar 10bit untuk mendapatkan ketelitian yang cukup.

Setup pengukuran adalah sebagai berikut: ruangan berukuran $5 \times 6$ meter, tinggi plafon 3 meter, sensor dipasang di tengah-tengah plafon. Pengukuran dibagi menjadi 3 skenario, yaitu: ruangan kosong, ruangan diisi benda tidak bergerak, ruangan diisi benda bergerak. Pada tulisan ini ditampilkan hasil pengukuran untuk ruangan kosong, ruangan berisi orang yang sedang berjalan kaki, kemudian ruangan diisi orang yang sedang duduk diam tanpa melakukan gerakan.

\section{Hasil dan Pembahasan}

Hasil pengukuran ditampilkan melalui gambargambar pola gema yang ditangkap dan hasil pengolahannya seperti yang ditampilkan pada Gambar 4. Gambar 4.a sampai dengan Gambar 4.1 memperlihatkan hasil pengukuran pola gema, dimana sumbu- $\mathrm{x}$ adalah besaran kuantisasi 10bit (0-1023) representasi amplitudo tegangan dari 0 sampai dengan 5volt, dan sumbu-y adalah urutan sampel (1-200) representasi waktu dari 0 sampai dengan $45 \mathrm{~ms}$.

Gambar 4.a sampai dengan 4.d menampilkan hasil pengukuran dan pengolahan pola gema ruangan yang dalam keadaan kosong. Gambar 4.a dan 4.b adalah dua buah pola gema yang diambil berurutan berselang sekitar sepertiga detik, kemudian 4.c merupakan hasil perbandingan pola gema dari gambar 4.a dan 4.b. Secara ideal pola gema pertama dan kedua tersebut adalah identik, energi yang masih terlihat pada Gambar 4.c merupakan noise yang tidak diinginkan dan dieliminasi dengan menambahkan threshold pada sistem, hasilnya seperti diperlihatkan pada gambar 4.d.

Dari pengukuran laboratorium seperti diperlihatkan pada Tabel 1 didapat noise yang tidak diinginkan rata-rata sekitar 11, maka jika threshold kita berikan di angka 15-20 sudah cukup baik.

Tabel 1. Pengukuran noise yang tidak diinginkan

\begin{tabular}{cccc}
\hline $\begin{array}{c}\text { Jumlah } \\
\text { pengukuran }\end{array}$ & $\begin{array}{c}\text { Nilai } \\
\text { terkecil }\end{array}$ & $\begin{array}{c}\text { Nilai } \\
\text { terbesar }\end{array}$ & $\begin{array}{c}\text { Nilai rata- } \\
\text { rata }\end{array}$ \\
\hline $\begin{array}{c}30 \text { pola, } \\
\text { jumlah data } \\
6000 \text { buah }\end{array}$ & 0 & 36 & 10.97 \\
\hline
\end{tabular}

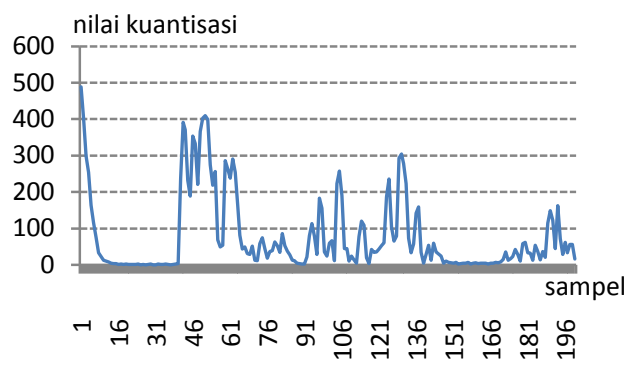

Gambar 4.a. Pola gema pertama, di ruang statis.

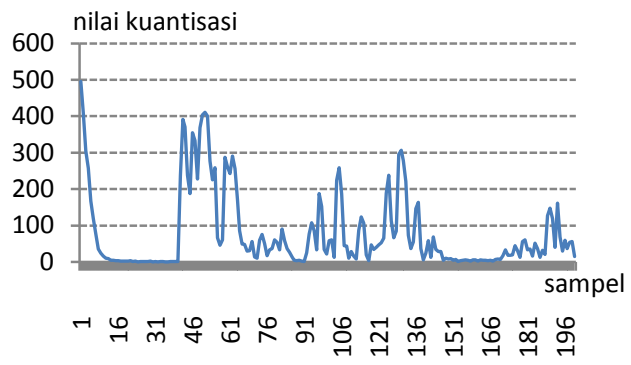

Gambar 4.b. Pola gema kedua, di ruang statis.

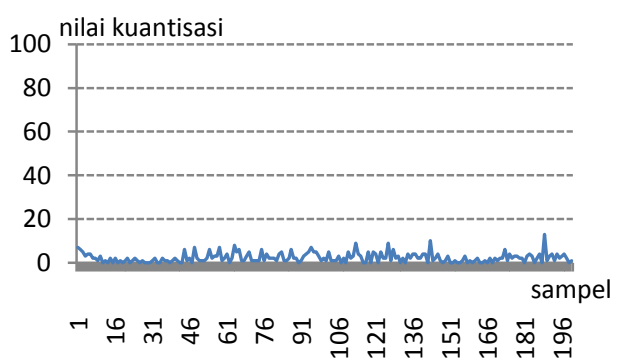

Gambar 4.c. Nilai absolut perbandingan gema pertama dan gema kedua. 


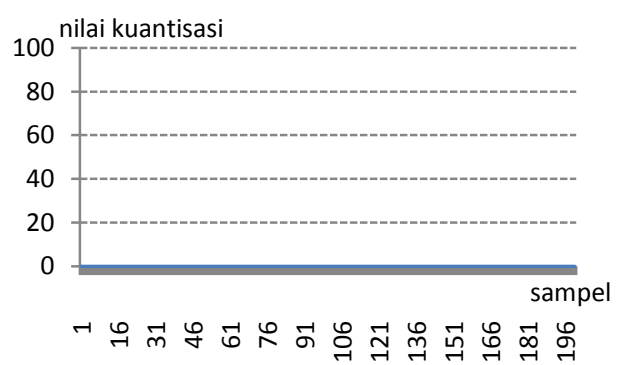

Gambar 4.d. Hasil setelah dikurangi threshold, jumlahnya adalah 0 .

Gambar 4.e sampai dengan Gambar 4.h menampilkan hasil pengukuran dan pengolahan pola gema ruangan yang didalamnya terdapat seseorang sedang melakukan gerakan berjalan. Gambar 4.e dan 4.h adalah dua buah pola gema yang diambil berurutan, kemudian 4.c merupakan hasil perbandingan pola gema dari gambar 4.e dan 4.f, energi yang terlihat pada gambar 4.g merupakan selisih kedua pola gema tersebut, dan gambar 4.h. merupakan grafik setelah threshold.

Dari pengukuran laboratorium seperti diperlihatkan pada Tabel 2 didapat nilai kuantisasi yang cukup besar dengan nilai kuantisasi terbesar adalah 668 dan nilai rata-rata sebesar 28869.

Tabel 2. Pengukuran orang berjalan

\begin{tabular}{cccc}
\hline $\begin{array}{c}\text { Jumlah } \\
\text { pengukuran }\end{array}$ & $\begin{array}{c}\text { Nilai } \\
\text { terkecil }\end{array}$ & $\begin{array}{c}\text { Nilai } \\
\text { terbesar }\end{array}$ & $\begin{array}{c}\text { Nilai } \\
\text { rata-rata }\end{array}$ \\
\hline $\begin{array}{c}\text { 24 pola, dgn } \\
\text { jumlah data } 4800 \\
\text { buah }\end{array}$ & 0 & 668 & 28869 \\
\hline
\end{tabular}

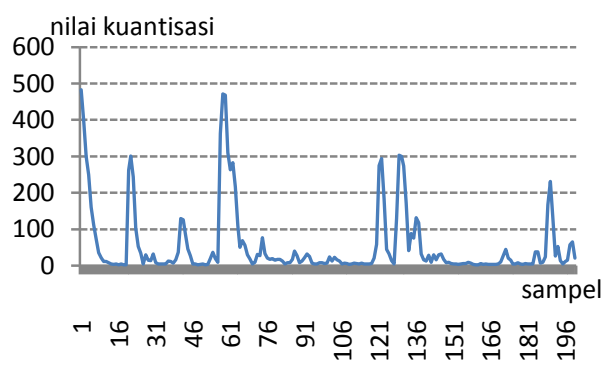

Gambar 4.e. Pola gema pertama, di ruang dinamis (orang sedang berjalan).

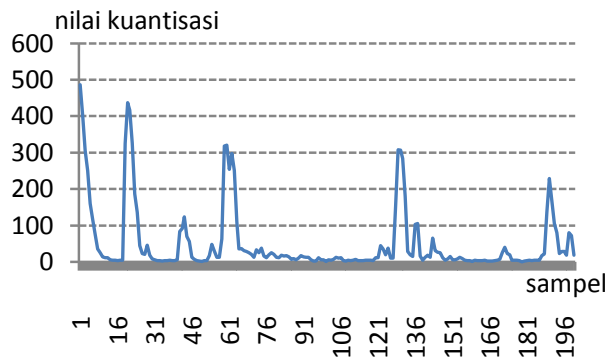

Gambar 4.f. Pola gema kedua, di ruang dinamis (orang sedang berjalan).

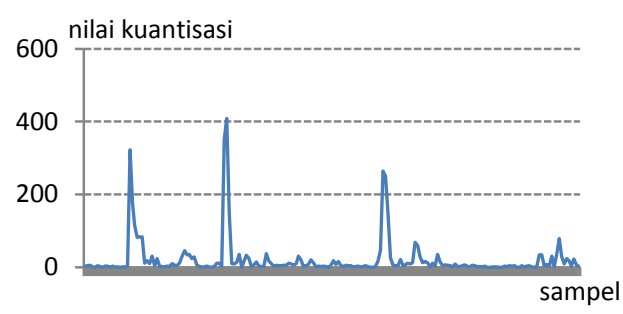

- 당

Gambar 4.g. Nilai absolut perbandingan gema pertama dan gema kedua.

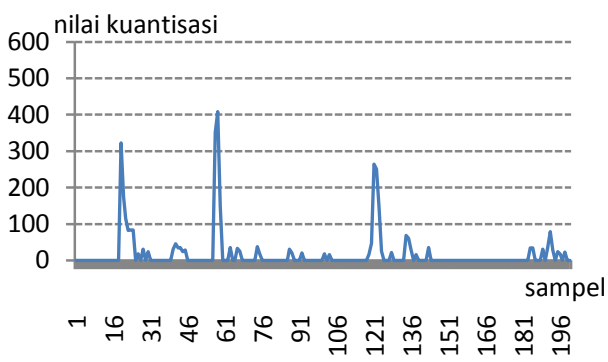

Gambar 4.h. Hasil setelah dikurangi threshold, jumlahnya adalah 3586 .

Gambar 4.i sampai dengan 4.1 menampilkan hasil pengukuran dan pengolahan pola gema ruangan yang didalamnya terdapat seseorang sedang duduk diam. Gambar 4.i dan 4.j adalah dua buah pola gema yang diambil berurutan, kemudian Gambar 4.k merupakan hasil perbandingan pola gema dari Gambar 4.i dan 4.j, energi yang terlihat pada Gambar 4.k merupakan selisih kedua pola gema tersebut, dan Gambar 4.1. merupakan grafik setelah threshold.

Dari pengukuran laboratorium seperti diperlihatkan pada Tabel 3 didapat nilai kuantisasi yang cukup besar dengan nilai kuantisasi terbesar adalah 242 dan nilai rata-rata sebesar 489 .

Tabel 3. Pengukuran orang diam

\begin{tabular}{cccc}
\hline $\begin{array}{c}\text { Jumlah } \\
\text { pengukuran }\end{array}$ & $\begin{array}{c}\text { Nilai } \\
\text { terkecil }\end{array}$ & $\begin{array}{c}\text { Nilai } \\
\text { terbesar }\end{array}$ & $\begin{array}{c}\text { Nilai rata- } \\
\text { rata }\end{array}$ \\
\hline $\begin{array}{c}30 \text { pola, dgn } \\
\text { jml data } \\
6000\end{array}$ & 0 & 242 & 489 \\
\hline
\end{tabular}




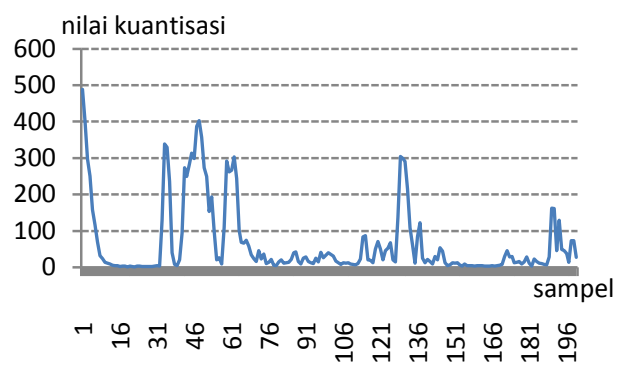

Gambar 4.i. Pola gema pertama di ruang dinamis (orang sedang duduk diam).

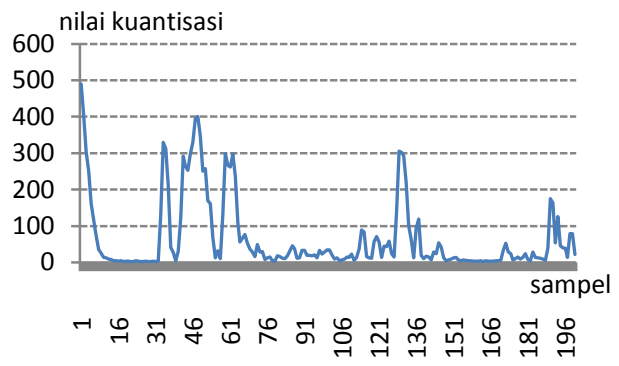

Gambar 4.j. Pola gema kedua di ruang dinamis (orang sedang duduk diam).

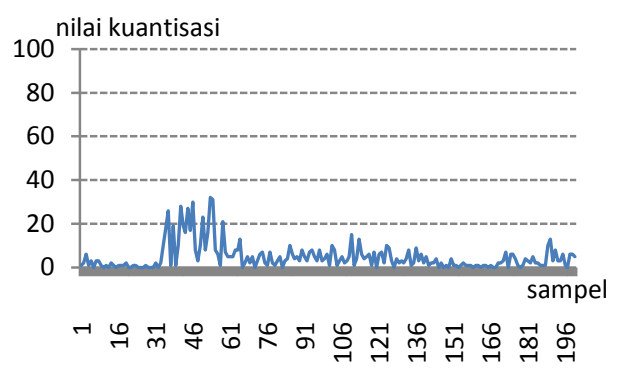

Gambar 4.k. Nilai absolut perbandingan gema pertama dan gema kedua.

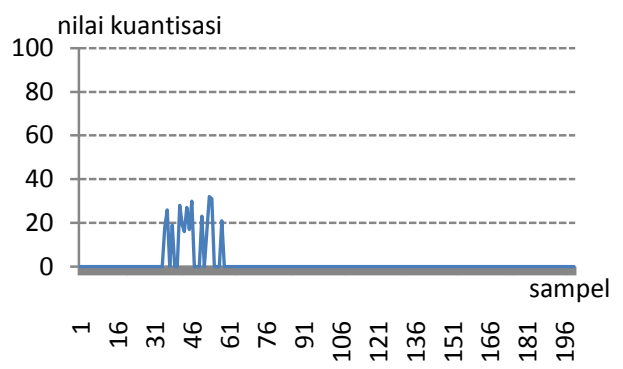

Gambar 4.l. Hasil setelah threshold jumlahnya 323.

\section{Kesimpulan}

Karena metoda pembandingan pola gema secara relatif merekam seluruh gema yang dipantulkan oleh objek-objek di area sensitif sensor, berbeda dengan metoda pulse echo ranging yang hanya melakukan pengukuran jarak terhadap objek terdekat saja, maka metoda pembandingan pola gema lebih efektif digunakan sebagai pendeteksi gerakan.

Dengan penekanan noise yang baik pada tranduser dan resolusi kuantisasi ADC yang tinggi, dapat dihasilkan pendeteksi gerakan yang mempunyai sensitifitas tinggi.

Dari hasil beberapa skenario pengukuran, untuk pengukuran gerakan-gerakan besar hingga gerakan-gerakan halus, didapatkan hasil yang cukup baik, sistem dapat mendeteksi gerakangerakan orang yang sedang berjalan dengan baik, terlihat dari perolehan selisih nilai kuantisasi yang cukup besar, dari 24 sampel pola gema yang diambil nilai perolehan rata-ratanya adalah 28689 . Kemudian sistem juga dapat mendeteksi gerakan orang bernafas dengan baik, dari 30 sampel didapat nilai perolehan rata-ratanya sebesar 489. Sedangkan untuk pengukuran ruangan kosong didapat nilai-nilai signifikan di sekitar $32-36$, dengan nilai rata-rata sekitar 11 , sehingga dapat digunakan nilai threshold diatas angka 15. Pada penelitian ini digunakan nilai threshold sebesar 20, dengan hasil yang cukup baik.

Pada pengukuran di laboratorium menggunakan transduser ultrasound jenis MaxBotix-1360[11] dan ADC 10bit dari controller board arduino uno[12], sistem cukup sensitif untuk dapat mendeteksi gerakan-gerakan tubuh manusia, dari mulai gerakan-gerakan yang besar seperti gerakan berjalan, hingga gerakan yang kecil seperti gerakan respirasi eksternal.

\section{Daftar pustaka}

[1] T. Teixeira, G. Dublon, and A. Savvides, "A Survey of Human Sensing: Methods for Detecting Presence, Count, Location, Track and Identity", ACM Computing Surveys, 2010.

[2] M.A. Troost, "Presence detection and activity recognition using low-resolution passive IR sensors", Technische Universiteit Eindhoven, 2013.

[3] Clare Chen, Grace Li, Peter Ngo, and Connie Sun, "Motion Sensing Technology", Management of Technology - E 103, Team Bazinga, 2011.

[4] Glolab Corporation, "Infrared Motion Detector Manual", 307 Pine Ridge Drive, Wappingers Falls, NY 12590, Glolab Corp, 2005.

[5] Sukhivinder Singh, Qilian Liang, and Dechang Chen, "Sense through Wall Human Detection Using UWB Radar", Dept. of Electrical Engineering, University of Texas at Arlington, Arlington, 2011.

[6] Leslie Hodges, "Ultrasonic and Passive Infrared Sensor Integration for Dual Technology User Detection Sensors", ECE 480 - Application Note, Michigan State University, 2009. 
[7] Don B Munroe, "Comparison of Watt Stopper'sPatented Dual Technology Sensor vs. Microphonics", http://www.wattstopper.com/, 2013, diakses tanggal 10-03-2013.

[8] Suzanne Amador Kane, "Ultrasound Imaging Physics", Physics Department, 370 Lancester Avenue, Haverford College, Haverford PA 19041, 2008.

[9] Victor Kremin, "Ultrasound Motion Sensor", Application Note - AN2047, Cypress MicroSystems, 2002.
[10] Kurt Inman, "What Is an Ultrasonic Motion Detector?", http://www.wisegeek.com/what-is-anultrasonic-motion-detector.htm, diakses tanggal 1003-2013.

[11]XL-MaxSonar®- EZ ${ }^{\text {TM }}$ Series High Performance Sonar Range Finder, MaxBotix Inc. USA, 2013.

[12] Masimo Banzi, "Getting Started with Arduino" Second Edition, O’Reilly, 2013. 
68 - INKOM, Vol. 8, No. 2, November 2014: 61-68 